1. Hand NJ, Master ZR, Le Lay J, Friedman JR. Hepatic function is preserved in the absence of mature microRNAs. Hepatology. 2009;49(2):618-626

2. Sekine S, et al. Disruption of Dicer1 induces dysregulated fetal gene expression and promotes hepatocarcinogenesis. Gastroenterology. 2009;136(7):2304-2315.e4.

3. Lagos-Quintana M, Rauhut R, Yalcin A, Meyer J, Lendeckel W, Tuschl T. Identification of tissue-specific microRNAs from mouse. Curr Biol. 2002;12(9):735-739.

4. Esau C, et al. miR-122 regulation of lipid metabolism revealed by in vivo antisense targeting. Cell Metab. 2006;3(2):87-98.

5. Krutzfeldt J, et al. Silencing of microRNAs in vivo with 'antagomirs'. Nature. 2005;438(7068):685-689.

6. Saito Y, et al. MicroRNAs in hepatobiliary and pancreatic cancers. Front Genet. 2011;2:66

7. Hsu S-H, et al. Essential metabolic, anti-inflammatory, and anti-tumorigenic functions of miR-122 in liver. J Clin Invest. 2012;122(8):2871-2883.

8. Tsai W-C, et al. MicroRNA-122 plays a critical role in liver homeostasis and hepatocarcinogenesis. J Clin Invest. 2012;122(8):2884-2897.

9. Kim YJ, Cho SY, Yun CH, Moon YS, Lee TR, Kim $\mathrm{SH}$. Transcriptional activation of Cidec by PPAR- gamma2 in adipocyte. Biochem Biophys Res Commun. 2008;377(1):297-302.

10. Hussain MM, Shi J, Dreizen P. Microsomal triglyceride transfer protein and its role in apoB-lipoprotein assembly. J Lipid Res. 2003;44(1):22-32.

11. Karlmark KR, et al. Hepatic recruitment of the inflammatory Gr1+ monocyte subset upon liver injury promotes hepatic fibrosis. Hepatology. 2009;50(1):261-274.

12. Miele L, et al. The Kruppel-like factor 6 genotype is associated with fibrosis in nonalcoholic fatty liver disease. Gastroenterology 2008;135(1):282-291.e1.

13. Wu X, et al. miR-122 affects the viability and apoptosis of hepatocellular carcinoma cells. Scand J Gastroenterol. 2009;44(11):1332-1339.

14. Coulouarn C, Factor VM, Andersen JB, Durkin ME, Thorgeirsson SS. Loss of miR-122 expression in liver cancer correlates with suppression of the hepatic phenotype and gain of metastatic properties. Oncogene. 2009;28(40):3526-3536.

15. Bai S, et al. MicroRNA-122 inhibits tumorigenic properties of hepatocellular carcinoma cells and sensitizes these cells to sorafenib. J Biol Chem. 2009;284(46):32015-32027.

16. McGlynn KA, London WT. Epidemiology and natural history of hepatocellular carcinoma. Best Pract
Res Clin Gastroenterol. 2005;19(1):3-23.

17. Laudadio I, et al. A feedback loop between the liverenriched transcription factor network and miR122 controls hepatocyte differentiation. Gastroenterology. 2012;142(1):119-129.

18. Machlin ES, Sarnow P, Sagan SM. Masking the $5^{\prime}$ terminal nucleotides of the hepatitis $\mathrm{C}$ virus genome by an unconventional microRNA-target RNA complex. Proc Natl Acad Sci U S A. 2011;108(8):3193-3198.

19. Nunnari G, Schnell MJ. MicroRNA-122: a therapeutic target for hepatitis $\mathrm{C}$ virus (HCV) infection. Front Biosci (Schol Ed). 2011;3:1032-1037.

20. Jopling CL. Regulation of hepatitis C virus by microRNA-122. Biochem Soc Trans. 2008; 36(Pt 6):1220-1223

21. Shimakami T, et al. Stabilization of hepatitis C virus RNA by an Ago2-miR-122 complex. Proc Natl Acad Sci US A. 2012;109(3):941-946.

22. Sarasin-Filipowicz M, Krol J, Markiewicz I, Heim $\mathrm{MH}$, Filipowicz W. Decreased levels of microRNA miR-122 in individuals with hepatitis C responding poorly to interferon therapy. Nat Med. 2009;15(1):31-33.

23. Lanford RE, et al. Therapeutic silencing of microRNA-122 in primates with chronic hepatitis C virus infection. Science. 2010;327(5962):198-201.

\title{
How many neutrophils are enough (redux, redux)?
}

\author{
Samuel C. Silverstein ${ }^{1,2}$ and Raul Rabadan 3,4
}

1Department of Physiology and Cellular Biophysics, ${ }^{2}$ Department of Medicine, ${ }^{3}$ Department of Biomedical Informatics, and ${ }^{4}$ Center for Computational Biology and Bioinformatics, College of Physicians and Surgeons, Columbia University, New York, New York, USA.

\begin{abstract}
Many chemotherapeutic regimens produce neutropenia, which predisposes to microbial infection. However, not all neutropenic individuals develop infections, so the ability to predict this outcome would be a powerful clinical tool. In this issue of the JCI, Malka et al. describe a dynamic system model of neutrophil bactericidal activity that confirms and extends the concept of critical neutrophil concentration. The authors demonstrate that when the neutrophil concentration approaches the critical concentration, bacterial populations in contact with them exhibit bistability. Their experimental findings raise the intriguing possibility of greater variability in bactericidal activity of neutrophils from healthy adults than heretofore recognized; their model predicts that this could have life-and-death consequences.
\end{abstract}

Although the link between neutropenia and infection risk is clear, the precise number of neutrophils required to maintain health remains a topic of intense research interest. Neutrophils continuously patrol the luminal surfaces of endothelial cells, searching for signs of infection or inflammation. Such signs stimulate them to emigrate from blood into extravascular compartments (1). There, their armamen-

Conflict of interest: Raul Rabadan is a consultant for Novartis and the Geneva Foundation. Samuel C. Silverstein owns stock in Roche Pharmaceuticals and Teva Pharmaceuticals.

Citation for this article: J Clin Invest. 2012; 122(8):2776-2779. doi:10.1172/JCI63939. tarium of chemoattractant and phagocytosis-promoting plasma membrane opsonin and pattern-recognition receptors enable them to phagocytose approximately 40-50 bacteria/neutrophil (2), and their preformed granule proteins and capacity to produce high intravacuolar concentrations of reactive oxygen species (3) enable them to kill their bacterial prey. The extracellular release of DNA-histone antimicrobial protein-containing nets (4) that entrap bacteria and kill yeast/fungi (5) extends their bactericidal and fungicidal activities into their afterlives and further enhances their efficacy as guardians of tissue sterility.
Chemotherapeutic agents that inhibit neutrophil biogenesis (6-8) and/or reduce their bactericidal activity (7) produce neutropenia (i.e., <500,000 neutrophils/ml blood). Although neutropenia predisposes to infection, it has little direct effect on the sterility of blood because under most (9) but not all (10) - conditions, hepatic and splenic macrophages are the cells primarily responsible for clearing bacteria from the circulation. Indeed, as suggested by Crosby (11) and supported by the studies of Wright et al. (12) and Koene et al. (13), it is the tissue neutrophil concentration $(N)$ that determines whether the small number of bacteria that breech mucosal surfaces each day will find fertile soil for growth, or be engulfed and killed. Thus, while a blood $N$ value of $5 \times 10^{5}$ neutrophils $/ \mathrm{ml}$ is a call for vigilance, it is an imprecise measure of the likelihood of infection. This is so because blood is primarily the conduit by which neutrophils travel from bone marrow to tissues, and the blood $N$ reflects the sum of the rates at which neutrophils are produced and released from bone marrow into the circulation, and the rates at which they are consumed in tissues (14) and/or recycled to spleen and bone marrow for destruction (15). 
A

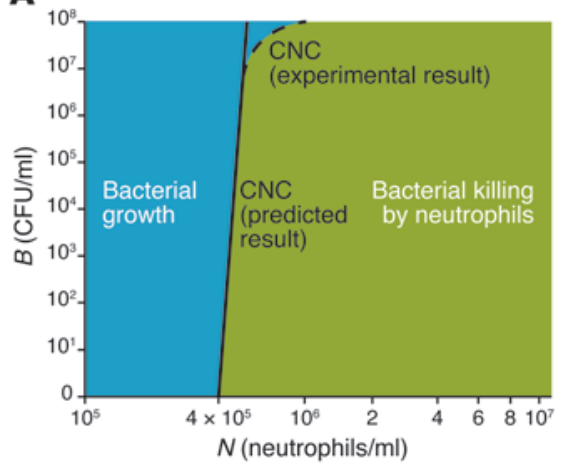

B

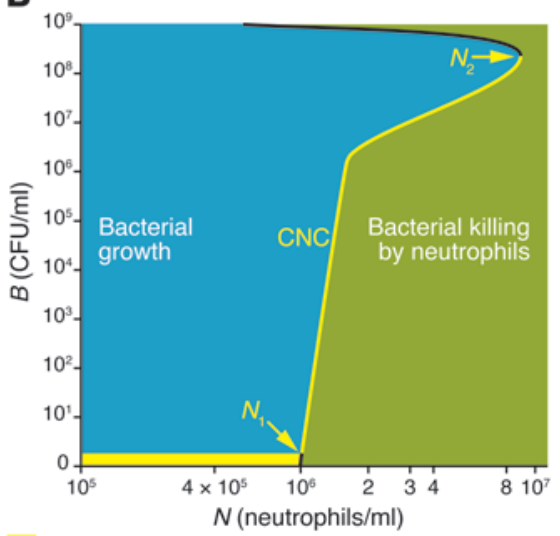

Unstable behavior

\section{A critical concentration of neutrophils is required to produce a net reduction in bacterial concentration}

Since Robertson and Sia's 1924 report (16), most in vitro studies of neutrophil-bactericidal activity have used neutrophils stirred continuously for $15-120$ minutes at $37^{\circ} \mathrm{C}$ in plasma- or serum-containing medium with known concentrations of bacteria. The neutrophils then are lysed, and the concentration of viable bacteria remaining is measured by bacteriological colony assay. This system mimics neutrophil-bactericidal activity in blood. Comparatively few investigators have studied neutrophil-bactericidal activity in tissues of living animals or in three-dimensional gels composed of extracellular matrix proteins. The findings that extracellular matrix proteins exert potent physiological effects on phagocytes $(17,18)$, and that the chemoattractant $N$-formyl-methionine-leucine-phenylalanine (fMLP) (19) inhibits neutrophil migration in fibrin-containing matrices, but not in collagen matrices, prompted Li et al. to examine neutrophil-bactericidal activity in tissues and tissue-like environments (20).

\section{Figure 1}

Comparative behaviors of bacterial populations at or near the CNC, as predicted by the equations of $\mathrm{Li}$ et al. $(20,21)$ and Malka et al. (25). (A) $\mathrm{Li}$ et al. derived an equation that includes an experimentally determined bacterial killing constant and the bacterial growth rate $(20,21)$. It predicts the CNC is constant at all $B$ values. Their experiments show, however, that the bacterial growth rate and killing constant decrease, and the CNC increases (curved dashed line), at $B$ values greater than $10^{7} \mathrm{CFU} / \mathrm{ml}$ in stirred suspension and greater than $10^{6}$ $\mathrm{CFU} / \mathrm{ml}$ in fibrin gel (not shown). Most importantly, this equation predicts $B$ will decrease or increase at all $N$ values below or above the $\mathrm{CNC}$, respectively, and remain constant at the CNC. (B) In contrast, as reported here by Malka et al., the bacterial population is bistable at $N$ at or very near the CNC, creating favorable conditions for uncontrolled bacterial growth (25). $N_{1}$ and $N_{2}$ and the dashed line indicate the $N$ and $B$ values that define the zone of bistability in the bacterial population. For $N$ below the CNC (solid yellow line), the bacterial population grows exponentially. Note also that in fibrin gels and rabbit dermis, the CNC at all $N$ values is at least 2-fold larger than in stirred suspensions, a reflection of the effect of the former environment on the bacterial killing constant.

They discovered that neutrophil-bactericidal activity in dermis of living rabbits and in fibrin gels is controlled by $N$ and is independent of bacterial concentration $(B)$, up to approximately $10^{6} \mathrm{CFU} / \mathrm{ml}(20)$. They derived an equation that describes bacterial killing as a function of $N$ and bacterial growth rate (Figure 1A) and showed that it accurately described neutrophil-bactericidal activity in suspension (21), fibrin gels, and dermis of living rabbits (20). Additionally, they found the ratio of the experimentally determined bacterial growth rate $(g)$ and neutrophil-bacterial killing rate constant $(k)$ defined a new and extremely useful parameter: the critical neutrophil concentration (CNC), namely, the $N$ required to hold $B$ constant (Figure $1 A$ and refs. 20,21). At $N$ values below the CNC, $B$ increases; at $N$ above the CNC, $B$ decreases. The $\mathrm{CNC}$ in stirred suspensions is approximately $4 \times 10^{5}$ neutrophils/ml (21), very close to the clinically determined value of $5 \times 10^{5}$ neutrophils/ml that defines neutropenia and characterizes neutropenic patients in danger of infection (6-8). The CNC in fibrin gels and rabbit dermis is approximately $1 \times 10^{6}$ and 8 $\times 10^{6}$ neutrophils $/ \mathrm{ml}$, respectively (20), 2 - to 20 -fold larger than in stirred suspensions. Apparently, evolution has taken note of the $\mathrm{CNC}$, as the blood neutrophil concentration is no less than approximately $5 \times 10^{5}$ neutrophils/ml in all adult vertebrates (22-24).

What is the physical meaning of the $\mathrm{CNC}$ ? The answer is evident from the value and units of $k(\mathrm{ml} /$ neutrophil/min), which for these purposes can be viewed as the volume of medium or tissue a neutrophil can explore per minute. For neutrophils in stirred suspension and in dermis of living rabbits, $k$ is equivalent to $2 \times 10^{-8}$ and $4 \times 10^{-9} \mathrm{ml} /$ neutrophil $/ \mathrm{min}$, respectively. In stirred suspension, 1 neutrophil can explore approximately $20 \mathrm{pl}$ medium/ min, whereas in rabbit dermis, it can only explore approximately $4 \mathrm{pl}$ dermis/min. Accordingly, $5 \times 10^{6}$ neutrophils $/ \mathrm{ml}$ - the average concentration in human blood - is required for these cells to explore 1 $\mathrm{ml}$ of a stirred bacterial suspension in 10 minutes (i.e., $2 \times 10^{-8} \mathrm{ml} /$ neutrophil $/ \mathrm{min}$ $\times 5 \times 10^{6}$ neutrophils $\times 10 \mathrm{~min}=1 \mathrm{ml}$ ). Likewise, $N$ of $2.5 \times 10^{7}$ neutrophils $/ \mathrm{ml}$ or neutrophils/g rabbit dermis is required for neutrophils to explore 1 milliliter or gram of dermis in 10 minutes. Higher concentrations of neutrophils or longer exploration times are required when $B$ exceeds $10^{7}$ per milliliter stirred suspension (21) or $10^{6}$ per milliliter or gram of tissue (20).

\section{Dynamic system model of neutrophil bactericidal activity: effects of bistability}

The equation Malka et al. report here (25) and previously (26), namely $d B(t) / d t=\rho B(t) /$ $[1+\beta B(t)]+s-\delta B(t)-(\alpha N B(t) /[1+\gamma B(t)+$ $\eta N]$ ), more accurately describes the rate of bacterial clearance than does the one previously reported by Li et al. $(20,21)$. This is because Malka et al. included the saturation rate for bacterial growth $(\beta)$ and the spontaneous rate of bacterial death $[\delta B(t)]$. The bacterial growth rate $(\rho)$ behaves like a carrying capacity and saturates $(\beta B)$ at high $B$ values. The authors also included in their equation the rates of bacterial influx into the circulation or site of infection(s) and of spontaneous bacterial death. If these rates could be measured, their inclusion would add significantly to the predictive power of the equation; however, there are no established methods at present for measuring them. Hence, Malka et al. assign them a value of 0 , thereby eliminating this difference between the two groups' equations. 
The equation's quadratic term represents the killing rate $(-\alpha N B(t) /[1+\gamma B(t)+\eta N])$. It involves the law of mass action: the neutrophil-bactericidal rate is proportional $(\alpha)$ to the product of $N$ and $B$ multiplied by the amount of time ( $t$; in minutes) the neutrophils interact with bacteria. It saturates at high concentrations of both neutrophils $(\eta N)$ and bacteria $(\gamma B)$. The system yields two very different outcomes depending on the magnitude of the initial parameters: it is monostable when $N$ is well above or below the critical concentration, but becomes bistable when $N$ fluctuates close to the CNC. Bistability is a characteristic of dynamic systems in which two stable coexisting fixed points exist for a range of parameters (Figure 1B), and the system's outcome depends on its initial conditions.

\section{Unresolved questions}

Although the equation derived by Malka et al. $(25,26)$ provides a more complete description of neutrophil-bactericidal activity than that of Li et al. (21), additional experiments are needed to assess its clinical utility. First, the conclusion that there is substantial patient-topatient variability in neutrophil-bactericidal activity relies on studies of the staphylococcicidal activity of neutrophils from only four healthy adults (25). Li et al. observed an approximately 2 -fold variation in values of $k$ and CNC for neutrophils from more than 20 healthy adult donors killing $S$. epidermidis in stirred solutions (21), and variations in these parameters of similar magnitude for neutrophils killing $S$. aureus, E. coli, and $P$. aeruginosa in stirred suspensions in studies are reported by others. Variations in neutrophil-bactericidal activity of this magnitude near or at the CNC are certainly sufficient to produce bistability in the bacterial population. Nonetheless, additional measurements of the efficiency of killing of both Gram-positive and -negative bacteria by neutrophils, from a larger number of uninfected and infected eupenic and neutropenic donors than was tested by Malka et al., are needed to define precisely the frequency and magnitude of variation in bactericidal activity of neutrophils. Second, the authors measured neutrophil-bactericidal activity in stirred suspensions (25), a condition that mimics neutrophil-bactericidal activity in blood. However, neutrophilbactericidal activity in tissues is of greatest relevance for neutropenic patients (8,
11-13). Thus, the method Malka et al. use might better predict the likelihood of infection in neutropenic patients if it employed fibrin gels to determine their neutrophils' bactericidal activity. Li et al. showed that the kinetics of neutrophilbactericidal activity in these gels closely mimics that for neutrophils in tissues in vivo (20). Third, Malka et al. ascribed the variability they observed in killing of $S$. aureus to differences in bactericidal activity of neutrophils from different healthy adult donors (25). However, their studies used $10 \%$ autologous serum, close to the concentration at which opsonin concentration becomes limiting $(21,27)$; $20 \%-40 \%$ serum would have been a better choice (21). Moreover, Malka et al. did not control for variations in opsonin concentration in each leukocyte donor's serum. Thus, the variations in killing efficiencies observed could reflect variations in serum opsonin concentrations $(27,28)$, not in neutrophil bactericidal activity. From both mechanistic and practical standpoints, this is an important matter to resolve.

Clinical experience now suggests that the use of G-CSF to prevent bone marrow-depressive effects of chemotherapy in patients at high risk for neutropenia is far more efficacious than using it to treat neutropenia once it has occurred $(8,29)$. Accordingly, it may be that the most useful clinical application of this new equation will be to use it prospectively in conjunction with other predictive tools (29), including low-tech methods such as the one devised by Wright et al. (12), to assess the likelihood that chemotherapy will cause the tissue bactericidal activity of a patient's neutrophils to fall below the CNC and/or into regions of bacterial bistability.

These concerns notwithstanding, we believe the findings that neutrophil-bactericidal activity can be described by equations very similar to those describing enzymesubstrate interactions provide an entirely new and quantitative way of viewing cellular defense against microbial pathogens. Budhu et al. reported that the equation described by Li et al. (21) also describes antigen-specific $\mathrm{CD}^{+} \mathrm{T}$ cell killing of cognate antigen-expressing melanoma cells in vitro and in living mice (30), which suggests that the same physical principles that govern neutrophil-bacterial interactions also govern the interactions of cytolytic lymphocytes with eukaryotic target cells. Indeed, it seems likely that these principles govern the effector activities of all immune cells. Consistent with this idea, Babbs (31) and Lejune et al. (32) report bistability of tumor cell growth under conditions in which the intratumoral concentration of tumor antigen-specific $\mathrm{CD}^{+} \mathrm{T}$ cells fluctuates around the critical $\mathrm{CD}^{+} \mathrm{T}$ cell concentration.

\section{Conclusions}

Malka et al. have derived a dynamic system model $(25,26)$ that describes neutrophilbactericidal activity in stirred solutions more accurately than did its linear predecessor $(20,21)$. Although further work is needed to determine whether the variability in bactericidal activity described for neutrophils from normal adults applies to neutrophils from neutropenic and/or cytotoxic drug-treated patients, this model may enable clinicians to better distinguish patients who are at risk of infection from those who are not, thereby reducing the morbidity, mortality, and expense associated with unnecessary hospitalizations and/or administration of antibiotics and/or G-CSF.

\section{Acknowledgments}

This work was supported by NIH grant AI-20516-026 to S.C. Silverstein and by grants U54 CA121852-05 from the NIH and 1R01LM010140-01 from the National Library of Medicine to R. Rabadan. The authors note that two previous reviews of neutropenia have used the approximate title, "How many neutrophils are enough?" $(11,33)$; hence their use of "redux, redux" in this title.

Address correspondence to: Samuel C. Silverstein, Department of Physiology and Cellular Biophysics, Columbia University College of Physicians and Surgeons, $630 \mathrm{~W}$. 168th Street, Rm. 11-411, New York, New York 10032, USA. Phone: 212.305.3546; Fax: 212.305.5775; E-mail: scs3@columbia.edu.

1. Muller WA. Mechanisms of transendothelial migration of leukocytes. Circ Res. 2009;105(3):223-230.

2. Leijh PC, van den Barselaar MT, van Zwet TL, Dubbeldeman-Rempt I, van Furth R. Kinetics of phagocytosis of Staphyloccocus aureus and Escherichia coli by human granulocytes. Immunology. 1979;37(2):453-465

3. Hampton MB, Kettle AJ, Winterboum CC. Inside the neutrophil phagosome: Oxidants, myeloperoxidase, and bacterial killing. Blood. 1998;92(9):3007-30017.

4. Ma AC, Kubes P. Platelets, neutrophils, and neutrophil extracellular traps (NETS) in sepsis. J Thromb Haemost. 2007;6(3):415-420.

5. Urban CF, et al. Neutrophil extracellular traps contain calprotectin, a cytosolic protein complex involved in host defense against Candida albicans. PLoS Pathog. 2009;5(10):e1000639. 
6. Bodey GP, Buckley M, Sathe YS, Freireich EJ. Quantitative relationship between circulating leukocytes and infection in patients with acute leukemia. Ann Intern Med. 1966;64(2):328-340.

7. Lejeune M, Sariban E, Cantineaux B, Ferster A, Devalck C, Fondu P. Granulocyte functions in children with cancer are differentially sensitive to the toxic effect of chemotherapy. Pediatr Res. 1996;39(5):835-842.

8. Crawford J, Dale DC, Lyman GH. Chemotherapy induced neutropenia. Cancer. 2003;100(2):228-243.

9. Benacerraf B, Sebestyen MM, Schlossman S. A quantitative study of the kinetics of blood clearance of P32-labeled Escherichia coli and Staphylococci by the reticuloendothelial system. J Exp Med. 1959;110(1):27-48.

10. Kurahashi K, et al. Depletion of phagocytes in the reticuloendothelial system causes increased inflammation and mortality in rabbits with Pseudomonas aeruginosa pneumonia. Am J Physiol Lung Cell Mol Physiol. 2009;296(2):L198-L209.

11. Crosby WH. Crosby WH. How many polys are enough? Arch Intern Med. 1969;123(4):722-723.

12. Wright DG, Meierovics AI, Foxley JM. Assessing the delivery of neutrophils to tissues in neutropenia. Blood. 1986;67(4):1023-1030.

13. Koene HR, de Haas M, Kleijer M, Huizinga TW, Roos D, von dem Borne AE. Clinical value of soluble IgG Fc receptor type III in plasma from patients with chronic idiopathic neutropenia. Blood. 1998;91(1):1-7.

14. Watson RWG, Redmond HP, Wang JH, Condron C, Bouchier-Hayes D. Neutrophils undergo apoptosis following ingestion of Escherichia coli.J Immunol. 1996;156(10):3986-3992.
15. Furze RC, Rankin SM. The role of the bone marrow in neutrophil clearance under homeostatic conditions in the mouse. FASEB J. 2008;22(9):3111-3119.

16. Robertson OH, Sia RHP. Studies on pneumococcus growth inhibition: ii. A method for demonstrating the growth-inhibitory and bactericidal action of normal serum-leucocyte mixtures. J Exp Med. 1924;39(2):219-244.

17. Wright SD, Licht MR, Craigmyle LP, Silverstein SC. Communication between receptors for different ligands on a single cell: Ligation of fibronectin receptors induces a reversible alteration in the function of complement receptors on cultured human monocytes. J Cell Biol. 1984;99(1 pt 1):336-339.

18. Nathan CF. Neutrophil activation on biological surfaces. J Clin Invest. 1987;80(6):1550-1560.

19. Li Y, et al. The bacterial peptide N-Formyl-MetLeu-Phe (fMLP) inhibits killing of Staphylococcus epidermidis by human neutrophils in fibrin gels. J Immunol. 2002;168(2):816-824.

20. Li Y, Karlin A, Loike J, Silverstein SC. A critical concentration of neutrophils is required to block growth of Staphylococcus epidermidis in fibrin gels. J Exp Med. 2004;200(5):613-622.

21. Li Y, Karlin A, Loike JD, Silverstein SC. A critical concentration of neutrophils is required for efficient bacterial killing in suspension. Proc Natl Acad SciU S A. 2002;99(12):8289-8294.

22. von Vietinghoff S, Ley K. Homeostatic regulation of blood neutrophil counts. I Immunol. 2008;181(8):5183-5188

23. Orun I, Dorusu M, Yaziak H. Haematological parameters of three Cyprinid fish species from Karakaya Dam Lake, Turkey. J Biol Sci. 2003; 3(3):320-328
24. Cutts LH, Krause WJ. Leukocytes in the blood of the developing opossum. J Anat. 1980; 130(pt 1):113-120.

25. Malka R, Wolach B, Gavrieli R, Shochat E, RomKedar V. Evidence for bistable bacteria-neutrophil interaction and its clinical implications. $J$ Clin Invest. 2012;122(8):3002-3011.

26. Malka R, Schochat E, Rom-Kedar V. Bistability and bacterial infections. PLoS One. 2010;5(5):1-10.

27. Johnston RB Jr, Klemperer MR, Alper CA, Rosen FS. The enhancement of bacterial phagocytosis by serum. The role of complement components and two cofactors. J Exp Med. 1969;129(6):1275-1290.

28. Brouwer N, et al. Mannose-binding lectin (MBL) substitution: Recovery of opsonic function in vivo lags behind MBL serum levels. J Immunol. 2009;183(5):3496-3504.

29. Aapro M, Crawford J, Kamioner D. Prophylaxis of chemotherapy-induced febrile neutropenia with granulocyte colony-stimulating factors: where are we now? Support Care Cancer. 2010;18(5):529-541.

30. Budhu S, et al. CD8+ T-cell concentration determines the efficiency of killing of cognate antigenexpressing syngeneic mammalian cells in vitro and in tissues. J Exp Med. 2010;207(1):223-235.

31. Charles FB. Predicting success or failure of immunotherapy for cancer: insights from a clinically applicable mathematical model. Am J Cancer Res. 2012;2(2):204-213.

32. Lejeune O, Chaplain MAJ, El Akili I. Oscillations and bistability in the dynamics of cytotoxic reactions mediated by the response of immune to solid tumors. Math Comput Model. 2008;47(5-6):649-662.

33. Dale DC, Liles C. How many neutrophils are enough? Lancet. 1998;351(9118):1752-1753. 